\title{
Field gamma-ray spectrometer GS256: measurements stability
}

\author{
Andrej MOJZEŠ 1 \\ ${ }^{1}$ Department of applied and environmental geophysics, Faculty of natural sciences, Comenius \\ University in Bratislava \\ Mlynská dolina, pav. G, SK-842 15 Bratislava, Slovak Republic; e-mail: mojzes@fns.uniba.sk
}

\begin{abstract}
The stability of in situ readings of the portable gamma-ray spectrometer GS256 during the field season of 2006 was studied. The instrument is an impulse detector of gamma rays based on $\mathrm{NaI}(\mathrm{Tl}) 3^{\prime \prime} \times 3^{\prime \prime}$ scintillation unit and 256-channel spectral analyzer which allows simultaneous assessment of up to 8 radioisotopes in rocks. It is commonly used in surface geophysical survey for the measurement of natural ${ }^{40} \mathrm{~K},{ }^{238} \mathrm{U}$ and ${ }^{232} \mathrm{Th}$ but also artificial ${ }^{137} \mathrm{Cs}$ quantities.

The statistical evaluation is given of both repeated measurements - in the laboratory and at several field control points in different survey areas. The variability of values shows both the instrument stability and also the relative influence of some meteorological factors, mainly rainfalls.

The analysis shows an acceptable level of instrument measurements stability, the necessity to avoid measurement under unfavourable meteorological conditions and to keep detailed field book information about time, position and work conditions.
\end{abstract}

Key words: ground gamma-ray spectrometry, concentrations of ${ }^{40} \mathrm{~K},{ }^{238} \mathrm{U}$ and ${ }^{232} \mathrm{Th}$ in near-surface layer, meteorological conditions, stability and repeatability of readings

\section{Introduction}

The time monitoring of the survey instrument behavior is of primary importance if the trustworthy and the most precise results are required and the time to cover the whole survey area is relatively long. One possibility for this observing are daily repeated measurements at the control (base) point usually located directly inside or very close to the survey area. This tracking is everyday part of the radiometry and gamma-ray spectrometry survey practice.

A further possibility is to continue the monitoring during survey pauses 
out of the survey area, e.g. in laboratory conditions. The large data sets are obtained to evaluate statistical variability at satisfactory level.

The results of statistical evaluation of repeated measurements are important not only from the point of the instrument functionality check but also from the point of their correlation with the variability of results obtained in the frame of single surveyed geological formations and structures and finally also from the point of assessment of meteorological changes influence during long-lasted exploration, mainly the influence of near-surface layer humidity as the result of rains and sun.

From the last mentioned factor it primarily follows that the enormous importance of the consistent management of detailed information on measurement condition in the field book.

\section{Object and area of study}

The measurement of ${ }^{40} \mathrm{~K},{ }^{238} \mathrm{U}$ and ${ }^{232} \mathrm{Th}$ concentrations was based on the gamma-ray detection. The spectrum energy lines commonly used in the field in situ measurements were applied. The determination of ${ }^{40} \mathrm{~K}$ is direct at the energy peak of $1.46 \mathrm{MeV}$ and the concentration is presented in $\% \mathrm{~K}$. The determination of ${ }^{238} \mathrm{U}$ and ${ }^{232} \mathrm{Th}$ is indirect, based on the detection of gamma-rays from disintegration of radon daughter products i.e. ${ }^{214} \mathrm{Bi}$ in case of ${ }^{238} \mathrm{U}$ at the energy peak of $1.76 \mathrm{MeV}$ and ${ }^{208} \mathrm{Tl}$ in case of ${ }^{232} \mathrm{Th}$ at the energy peak of $2.62 \mathrm{MeV}$. Their concentrations are presented in ppm eU (equivalent uranium), resp. ppm eTh (equivalent thorium).

The objective is the statistical evaluation of repeated measurements with the portable gamma-ray spectrometer GS256:

- in laboratory conditions before, during pauses in between and after survey periods,

- at 2 control (base) stations during survey works,

their mutual correlation and an attempt to assess the meteorological influences.

The survey works were performed as profile measurements in selected parts where the uranium mineralization is expected in the surroundings 


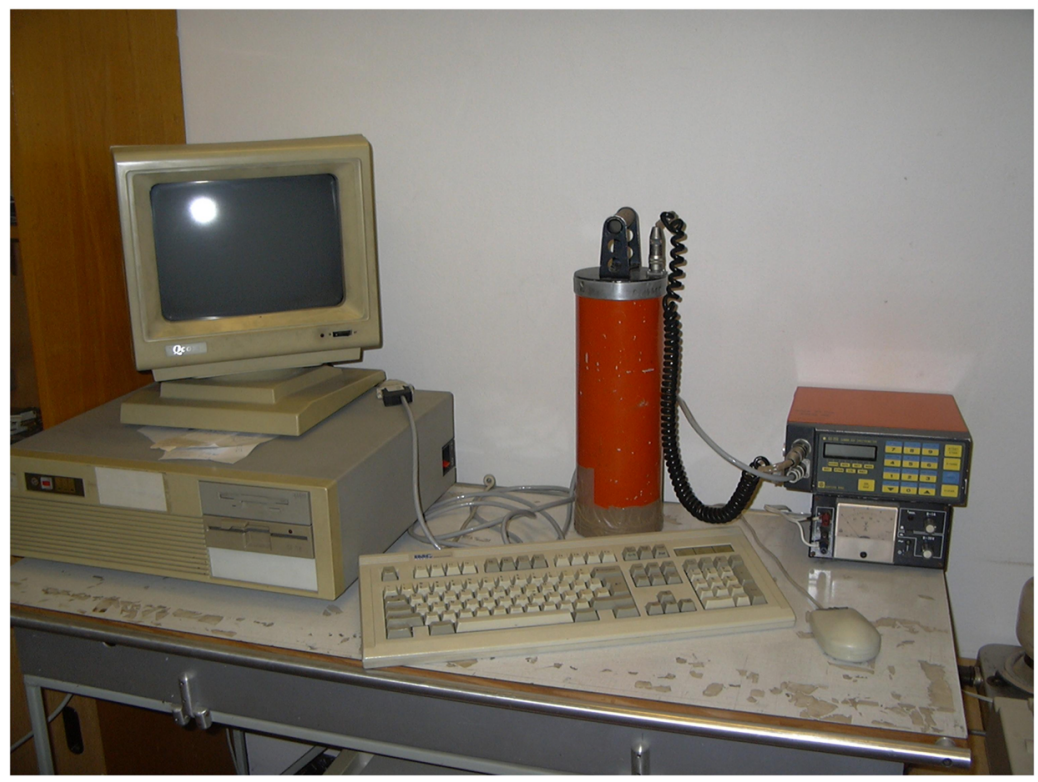

Fig. 1. Automated gamma-ray spectrometer GS256 measurements in laboratory conditions.

of the Kálnica and Selec villages in the Považský Inovec Mts. The uranium mineralization is bounded on Permian formations of cover nappe systems. Both areas are known by uranium mining in recent past. The survey was carried out in 4 periods: 2.-5.6.2006, 10.-12.6.2006, 21.-24.9.2006 and 28.9.-2.10.2006. Laboratory repeated measurements covered the period from 18.5.2006 to 3.10.2006.

\section{Results of study and discussion}

\subsection{Laboratory measurements}

The laboratory measurements do not mean the measurements of rock samples from the survey area but "background" measurements in the laboratory in the same geometry as in the field i.e. in the geometry of infinite source (Fig. 1). They were carried out at the Department of Applied and Environmental Geophysics at the Faculty of Natural Sciences, Comenius University in Bratislava and covered the whole period of field survey. Single 
Table 1. Basic statistical parameters of laboratory measurements

\begin{tabular}{|c|c|c|c|c|c|c|c|c|c|c|c|c|c|}
\hline \multirow{2}{*}{$\begin{array}{l}\text { Date } \\
2006\end{array}$} & \multirow{2}{*}{$\begin{array}{c}\text { No. } \\
\text { of } \\
\text { meas. }\end{array}$} & \multicolumn{3}{|c|}{$\begin{array}{c}\text { Total gamma } \\
\text { [Ur] }\end{array}$} & \multicolumn{3}{|c|}{$\begin{array}{c}\text { Potassium } \\
{[\% \mathrm{~K}]}\end{array}$} & \multicolumn{3}{|c|}{$\begin{array}{c}\text { Uranium } \\
{[\mathrm{ppm} \mathrm{eU]}}\end{array}$} & \multicolumn{3}{|c|}{$\begin{array}{c}\text { Thorium } \\
{[\mathrm{ppm} \text { eTh] }}\end{array}$} \\
\hline & & $\varnothing$ & $\sigma$ & $\omega$ & $\varnothing$ & $\sigma$ & $\omega$ & $\varnothing$ & $\sigma$ & $\omega$ & $\varnothing$ & $\sigma$ & $\omega$ \\
\hline 18.5 . & 36 & 15.98 & 0.14 & 0.01 & 2.55 & 0.06 & 0.02 & 3.14 & 0.20 & 0.06 & 7.70 & 0.33 & 0.04 \\
\hline 24.5 . & 39 & 15.98 & 0.13 & 0.01 & 2.56 & 0.05 & 0.02 & 3.12 & 0.20 & 0.07 & 7.74 & 0.42 & 0.06 \\
\hline 31.5 . & 37 & 15.98 & 0.09 & 0.01 & 2.56 & 0.04 & 0.02 & 3.11 & 0.19 & 0.06 & 7.81 & 0.41 & 0.05 \\
\hline 7.6. & 34 & 16.00 & 0.11 & 0.01 & 2.57 & 0.04 & 0.02 & 3.11 & 0.18 & 0.06 & 7.75 & 0.34 & 0.04 \\
\hline 13.6 . & 38 & 16.00 & 0.11 & 0.01 & 2.57 & 0.05 & 0.02 & 3.14 & 0.22 & 0.07 & 7.75 & 0.32 & 0.04 \\
\hline 23.6 . & 37 & 15.96 & 0.11 & 0.01 & 2.56 & 0.03 & 0.01 & 3.07 & 0.20 & 0.07 & 7.64 & 0.41 & 0.05 \\
\hline 30.6 . & 37 & 15.91 & 0.13 & 0.01 & 2.55 & 0.04 & 0.02 & 3.06 & 0.18 & 0.06 & 7.73 & 0.31 & 0.04 \\
\hline 7.7. & 30 & 15.88 & 0.10 & 0.01 & 2.54 & 0.05 & 0.02 & 3.13 & 0.26 & 0.08 & 7.72 & 0.38 & 0.05 \\
\hline 14.7. & 24 & 15.87 & 0.09 & 0.01 & 2.56 & 0.05 & 0.02 & 3.12 & 0.19 & 0.06 & 7.63 & 0.38 & 0.05 \\
\hline 20.7 . & 28 & 15.93 & 0.13 & 0.01 & 2.54 & 0.05 & 0.02 & 3.13 & 0.19 & 0.06 & 7.74 & 0.30 & 0.04 \\
\hline 1.8. & 30 & 15.91 & 0.11 & 0.01 & 2.55 & 0.06 & 0. & 3.10 & 0.20 & 0.06 & 7.67 & 0.24 & 0.03 \\
\hline 8.8. & 31 & 15.93 & 0.10 & 0.01 & 2.55 & 0.04 & 0.02 & 3.12 & 0.19 & 0.06 & 7.83 & 0.40 & 0.05 \\
\hline 22.8 . & 27 & 15.94 & 0.12 & 0.01 & 2.57 & 0.04 & 0.02 & 3.10 & 0.23 & 0.08 & 7.70 & 0.37 & 0.05 \\
\hline 31.8. & 23 & 15.96 & 0.12 & 0.01 & 2.58 & 0.05 & 0.02 & 3.03 & 0.14 & 0.05 & 7.80 & 0.36 & 0.05 \\
\hline 5.9. & 32 & 15.87 & 0.10 & 0.01 & 2.55 & 0.05 & 0.02 & 3.05 & 0.16 & 0.05 & 7.77 & 0.34 & 0.04 \\
\hline 12.9. & 31 & 15.88 & 0.12 & 0.01 & 2.55 & 0.05 & 0.02 & 3.08 & 0.22 & 0.07 & 7.72 & 0.33 & 0.04 \\
\hline 20.9 . & 22 & 15.94 & 0.10 & 0.01 & 2.55 & 0.04 & 0.02 & 3.14 & 0.20 & 0.06 & 7.72 & 0.31 & 0.04 \\
\hline 26.9. & 34 & 15.89 & 0.11 & 0.01 & 2.56 & 0.05 & 0.02 & 3.10 & 0.23 & 0.08 & 7.66 & 0.34 & 0.04 \\
\hline 3.10 . & 33 & 15.85 & 0.10 & 0.01 & 2.54 & 0.04 & 0.02 & 3.14 & 0.21 & 0.07 & 7.65 & 0.34 & 0.05 \\
\hline all & 603 & 15.93 & 0.12 & 0.01 & 2.56 & 0.05 & 0.02 & 3.11 & 0.20 & 0.07 & 7.72 & 0.35 & 0.05 \\
\hline
\end{tabular}

Legend: $\varnothing-$ mean,

$\sigma$ - standard deviation,

$\omega$ - coefficient of variation,

$\mathrm{Ur}-$ unit of concentration of equivalent uranium (1 $\mathrm{Ur} \sim 1 \mathrm{ppm} \mathrm{eU})$.

measurements were automated using the remote connection between instrument and desktop PC based on BASIC (MS-DOS) routine (Fig. 1). Whole monitored period from 18.5.2006 to 3.10.2006 consisted of 19 measurement days (Table 1). One measurement day usually consisted of 22-39 10-minute measurements so the daily measurement cycle lasted approx. 4-6 hours. All measurements were located at the same place and in the same geometry. There were 603 measurements performed in all. The basic statistical parameters of this data set are presented in Table 1. The time course of results is presented in Fig. 2.

The results of repeated measurements in laboratory show very high stability and low variability thanks to good instrument functionality, relatively long measurement time (10 minutes) and the absence of meteorological changes. As usually, the lowest variability is exhibited by potas- 

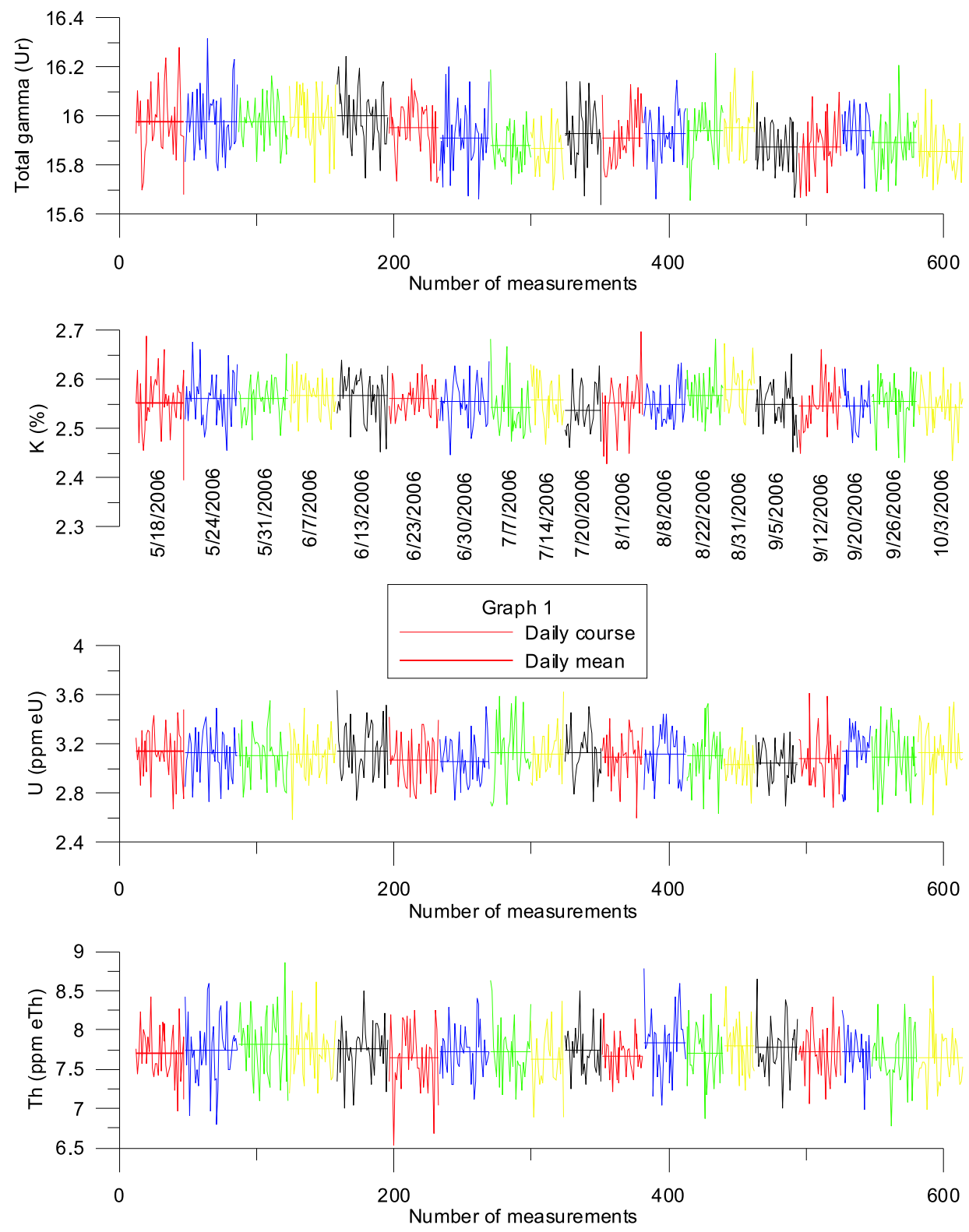

Fig. 2. Results of automated gamma-ray spectrometer GS256 measurements in laboratory conditions. 
sium K (standard deviation $\sigma= \pm 0.05 \% \mathrm{~K}$ ) followed by total gamma ( $\sigma= \pm 0.12 \mathrm{Ur}$ ), uranium ( $\sigma= \pm 0.2 \mathrm{ppm} \mathrm{eU})$ and the highest one by thorium $(\sigma= \pm 0.35 \mathrm{ppm} \mathrm{eTh})$. These values are even lower than the typical ones $( \pm 0.1 \% \mathrm{~K}, \pm 0.3 \mathrm{ppm}$ eU and $\pm 0.6 \mathrm{ppm}$ eTh$)$ for the same model of portable gamma-ray spectrometers (IAEA, 1990).

\subsection{Field measurements - control (base) stations}

The control (base) stations in the field survey are usually chosen to be easily accessible during daily measurements in the area. The control measurements at such points are usually done every day in the morning before the survey, in the evening after the survey and if requested also in the middle of daily measurements in the area. The technique of the control measurements should be identical to the survey one, i.e. the same time of accumulation, the stations should be located at the surface of natural geological environment (not at made-up ground), with the top-layer of soil humus and grass removed and with horizontal leveled surface inside $2 \mathrm{~m}$ radius in the open air site.

As the survey area in the Považský Inovec Mts. was composed of 2 parts, 2 control stations were arranged: KB9999 (N 48 $45^{\prime} 42.0^{\prime \prime}$, E $17^{\circ} 54^{\prime} 29.6^{\prime \prime}$ ) was located near to the Kálnica Village and KB9998 (N $48^{\circ} 49^{\prime} 08.3^{\prime \prime}$, E $\left.17^{\circ} 59^{\prime} 26.2^{\prime \prime}\right)$ near to the Selec Village. From 2 to 62 -minute measurements were usually carried out both in the morning and in the evening. There were 62 measurements done at the KB9999 and 64 measurements at the KB9998 in all. The basic statistical parameters of data sets measured during survey are presented in Table 2 .

A strong influence of natural meteorological parameters on the measurement stability can be inferred from the table. It is especially visible when compared with the laboratory results. Only the values of standard deviation of potassium concentration $( \pm 0.12 \% \mathrm{~K}$ and $\pm 0.09 \% \mathrm{~K})$ reach the typical level of $\pm 0.1 \% \mathrm{~K}$ (IAEA, 1990). These levels are highly exceeded by the other measured quantities. This dependence is generally known and considered as an important reason why the ground radiometry and gamma-ray spectrometry survey should not be carried out during extreme and inappropriate climatic and meteorological conditions, i.e. in autumn, winter and spring periods with low daily temperature, on snow cover, during long-lasted 
Table 2. Basic statistical parameters of control (base) station measurements

\begin{tabular}{|c|c|c|c|c|c|c|c|c|c|c|c|c|c|}
\hline \multirow{2}{*}{$\begin{array}{l}\text { Date } \\
2006\end{array}$} & \multirow{2}{*}{$\begin{array}{c}\text { No. } \\
\text { of } \\
\text { meas. }\end{array}$} & \multicolumn{3}{|c|}{$\begin{array}{c}\text { Total gamma } \\
\text { [Ur] }\end{array}$} & \multicolumn{3}{|c|}{$\begin{array}{c}\text { Potassium } \\
{[\% \mathrm{~K}]}\end{array}$} & \multicolumn{3}{|c|}{$\begin{array}{c}\text { Uranium } \\
\text { [ppm eU] }\end{array}$} & \multicolumn{3}{|c|}{$\begin{array}{c}\text { Thorium } \\
\text { [ppm eTh] }\end{array}$} \\
\hline & & $\varnothing$ & $\sigma$ & $\omega$ & $\varnothing$ & $\sigma$ & $\omega$ & $\varnothing$ & $\sigma$ & $\omega$ & $\varnothing$ & $\sigma$ & $\omega$ \\
\hline \multicolumn{14}{|c|}{ Control station KB9999 } \\
\hline 2.6 . & 7 & 15.20 & 0.69 & 0.05 & 1.70 & 0.12 & 0.07 & 3.73 & \begin{tabular}{|l|c|}
0.62 \\
\end{tabular} & 0.17 & 10.28 & 0.67 & 0.07 \\
\hline 3.6 . & 8 & 14.90 & 0.22 & 0.02 & \begin{tabular}{|l|l}
1.77 \\
\end{tabular} & 0.07 & 0.04 & 3.39 & 0.38 & 0.11 & 10.75 & 1.18 & 0.11 \\
\hline 4.6. & 10 & 15.52 & 0.78 & 0.05 & 1.70 & 0.10 & 0.06 & 4.10 & 1.38 & 0.34 & 10.66 & 0.89 & 0.08 \\
\hline 5.6 . & 10 & 14.94 & 0.34 & 0.02 & 1.78 & 0.09 & 0.05 & 3.05 & 0.40 & 0.13 & 11.12 & 0.94 & 0.08 \\
\hline 10.6 . & 10 & 15.57 & 0.52 & 0.03 & 1.83 & 0.09 & 0.05 & 3.78 & 0.93 & 0.25 & 10.75 & 0.88 & 0.08 \\
\hline 11.6. & 8 & 15.64 & 0.28 & 0.02 & 1.87 & 0.09 & 0.05 & 3.08 & \begin{tabular}{|l|l|}
0.46 \\
\end{tabular} & 0.15 & 11.71 & 1.09 & 0.09 \\
\hline 12.6 . & 9 & 15.85 & 0.33 & 0.02 & 1.91 & 0.10 & 0.05 & 3.17 & 0.44 & 0.14 & 11.51 & 0.65 & 0.06 \\
\hline all & 62 & 15.38 & 0.58 & 0.04 & 1.79 & 0.12 & 0.07 & 3.48 & 0.83 & 0.24 & 10.98 & 0.98 & 0.09 \\
\hline \multicolumn{14}{|c|}{ Control station KB9998 } \\
\hline 21.9 . & 7 & 16.06 & 0.26 & 0.02 & 1.85 & 0.13 & 0.07 & 3.43 & \begin{tabular}{|l|l|}
0.45 \\
\end{tabular} & 0.13 & 11.55 & 0.40 & 0.04 \\
\hline 22.9 . & 8 & 16.10 & 0.37 & 0.02 & 1.92 & 0.05 & 0.03 & 3.61 & 0.79 & 0.22 & 11.48 & 1.26 & 0.11 \\
\hline 23.9 . & 8 & 16.35 & 0.22 & 0.01 & 1.95 & 0.10 & 0.05 & 3.51 & 0.60 & 0.17 & 11.60 & 0.75 & 0.07 \\
\hline 24.9 . & 7 & 16.65 & 0.52 & 0.03 & 1.93 & 0.05 & 0.02 & 3.91 & 0.75 & 0.19 & 11.73 & 1.08 & 0.09 \\
\hline 28.9 . & 6 & 16.65 & 0.27 & 0.02 & 1.96 & 0.11 & 0.06 & 3.61 & 0.35 & 0.10 & 11.93 & 0.60 & 0.05 \\
\hline 29.9 . & 8 & 16.01 & 0.33 & 0.02 & 1.86 & 0.05 & 0.03 & 3.57 & 0.45 & 0.13 & 11.24 & 0.78 & 0.07 \\
\hline 30.9 . & 8 & 16.43 & 0.35 & 0.02 & 1.94 & 0.12 & 0.06 & 3.63 & 0.64 & 0.18 & 11.08 & 1.81 & 0.16 \\
\hline 1.10 . & 8 & 16.65 & 0.34 & 0.02 & 1.92 & 0.11 & 0.06 & 3.62 & 0.41 & 0.11 & 12.21 & 0.70 & 0.06 \\
\hline 2.10 . & 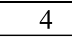 & 16.64 & 0.19 & 0.01 & 1.91 & 0.04 & 0.02 & 4.30 & 0.69 & 0.16 & 9.71 & 0.53 & 0.06 \\
\hline all & 64 & 16.37 & 0.41 & 0.03 & 1.92 & 0.09 & 0.05 & 3.65 & 0.59 & 0.16 & 11.47 & 1.10 & 0.10 \\
\hline
\end{tabular}

Legend: $\varnothing \quad-$ mean,

$\sigma$ - standard deviation,

$\omega$ - coefficient of variation,

$\mathrm{Ur}-$ unit of concentration of equivalent uranium (1 Ur $\sim 1 \mathrm{ppm} \mathrm{eU})$.

rainy periods when the near-surface layer is drenched, but also in the case of short but very intensive stormy rains. High summer temperatures have also some influence when the near-surface layer is intensively dried.

Some of the above mentioned extreme meteorological influences were taking part during the survey works in the study area. Mainly the summer storms with accompanying heavy rains in the mountain terrain, the temperature inversions in valleys with strong morning dews or the intensive soil drying in the afternoon and evening hours during hot sunny days. The valuable information on measurement conditions was obtained from the field books. The second source of information about extreme values at the control stations were the pictures of time changes of measured quantities during the day. As an example, the daily courses of uranium concentra- 
tion at both control stations during single survey periods are presented in Figs. 3-6.

Through the analysis of statistical values in Table 2, the graphic representations of the total gamma-activity, the concentrations of K, U (Figs. 3-6) and Th at the control stations in the day course and the field books, some extreme values and their probable reasons were identified:

- intensive summer storms with rains mainly in June (2.6., 4.6. and 10.6.),

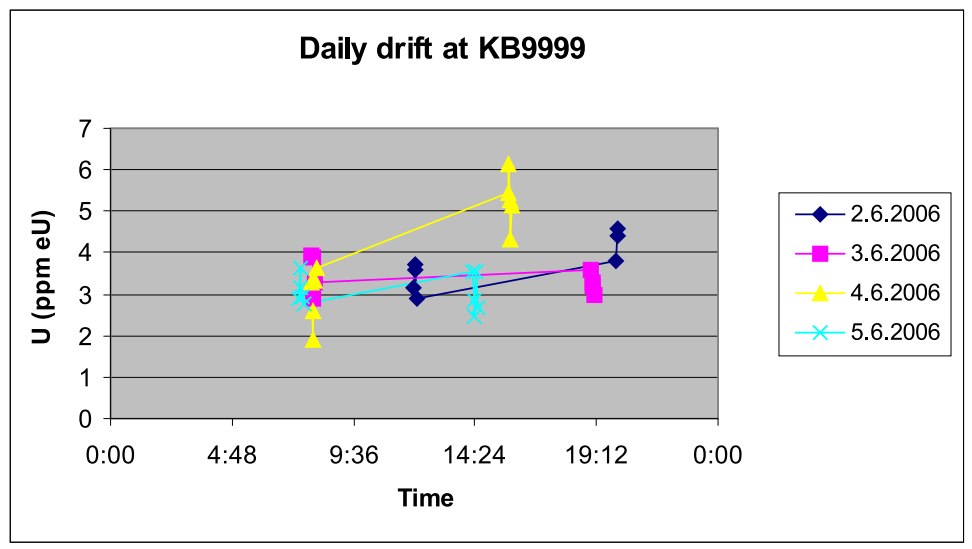

Fig. 3. Daily changes in U window at KB9999 during the period 2.-5.6.2006.

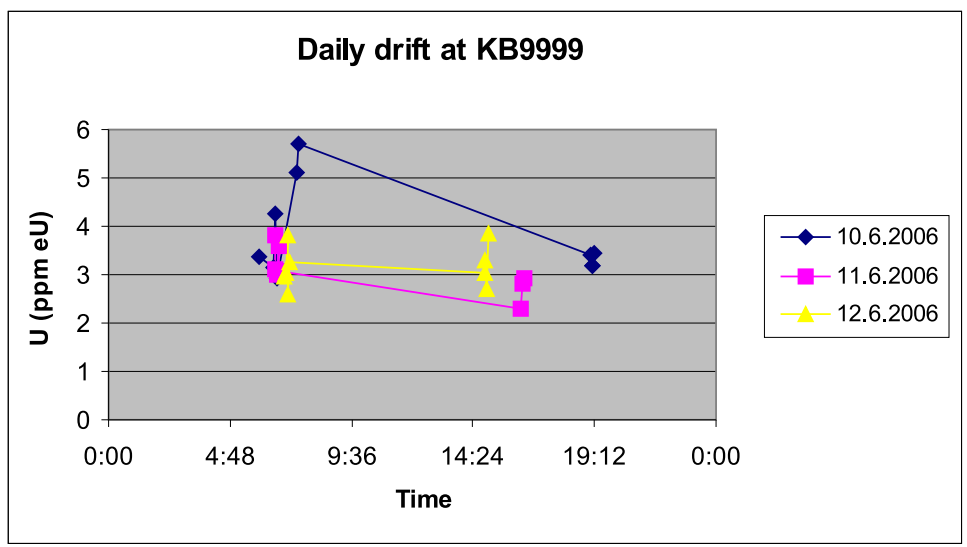

Fig. 4. Daily changes in U window at KB9999 during the period 10.-12.6.2006. 
less in October (2.10.),

- strong morning dews influencing soil humidity in September (23.9., 24.9., 30.9.),

- soil drying during sunny days in the afternoon and evening hours (22.9.).

These influences are demonstrated most clearly in the U window through the increase of values proportionally to the increase of cover humidity (rains, dew) which is connected with the washing of the daughter products of the

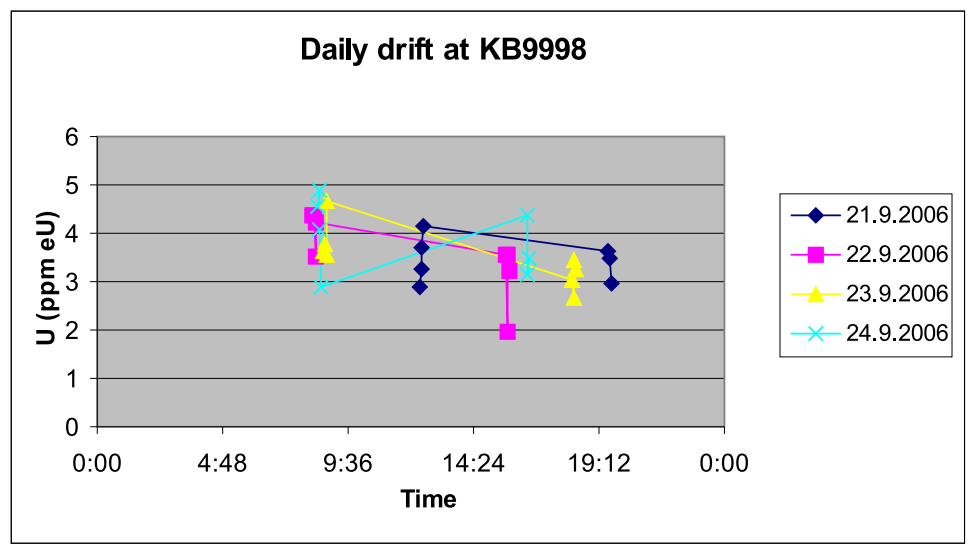

Fig. 5. Daily changes in U window at KB9998 during the period 21.-24.9.2006.

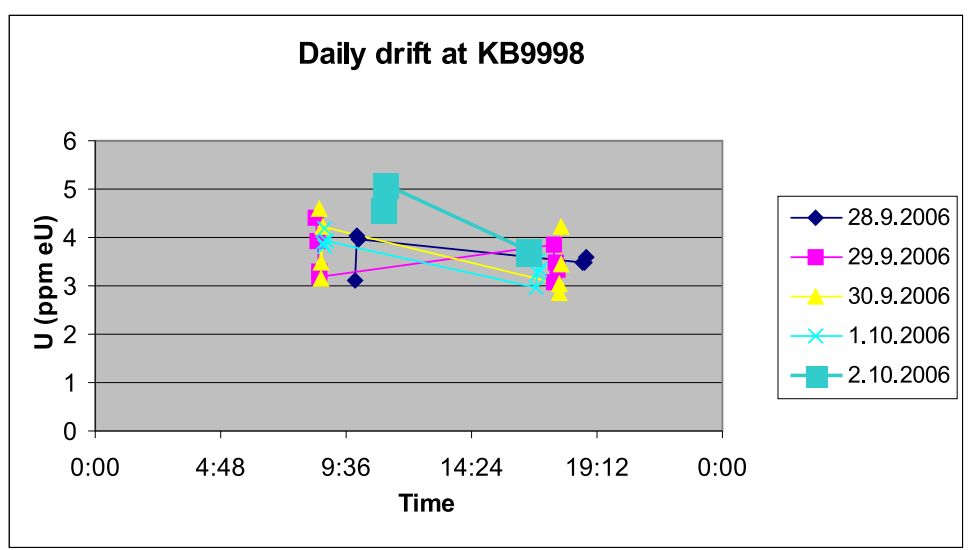

Fig. 6. Daily changes in U window at KB9998 during the period 28.9.-2.10.2006. 
atmospheric radon ${ }^{222} \mathrm{Rn}$ down to the soil and through the decrease of values in dry conditions. The changes in the wide spectral window of the total gamma-activity show similar features. As mentioned, the values in the $\mathrm{K}$ window show good stability also in natural conditions. It seems the values in the Th window show more statistical dependence than the dependence on natural conditions, i.e. their dependence on meteorological changes is not clearly legible.

After the exclusion of all extreme values measured at both control stations KB9999 and KB9998 as the result of the above mentioned meteorological changes the new statistical parameters were calculated as presented in Table 3.

Table 3. Basic statistical parameters of control (base) station measurements after exclusion of extreme values

\begin{tabular}{|c|c|c|c|c|c|c|c|c|c|c|c|c|c|c|c|c|}
\hline \multirow{2}{*}{$\begin{array}{l}\text { Date } \\
2006\end{array}$} & \multicolumn{4}{|c|}{$\begin{array}{l}\text { Total gamma } \\
\text { [Ur] }\end{array}$} & \multicolumn{4}{|c|}{$\begin{array}{c}\text { Potassium } \\
{[\% \mathrm{~K}]}\end{array}$} & \multicolumn{4}{|c|}{$\begin{array}{l}\text { Uranium } \\
{[\mathrm{ppm} \mathrm{eU}]}\end{array}$} & \multicolumn{4}{|c|}{$\begin{array}{c}\text { Thorium } \\
\text { [ppm eTh] }\end{array}$} \\
\hline & $\mathrm{N}$ & $\varnothing$ & $\sigma$ & $\omega$ & $\mathrm{N}$ & $\varnothing$ & $\bar{\sigma}$ & $\omega$ & $\mathrm{N}$ & $\varnothing$ & $\sigma$ & $\omega$ & $\mathrm{N}$ & $\varnothing$ & $\bar{\sigma}$ & $\omega$ \\
\hline \multicolumn{17}{|c|}{ Control station KB9999 } \\
\hline 2.6 . & 4 & 4.68 & 0.15 & 0.01 & 7 & 1.70 & 0.12 & 0.07 & 4 & 3.34 & 0.38 & 0.11 & 7 & 10.28 & 0.67 & 0.07 \\
\hline 3.6 . & 8 & 14.90 & 0.22 & 0.02 & 8 & 1.77 & 0.07 & 0.04 & 8 & 3.39 & 0.38 & 0.11 & 6 & 10.76 & 0.58 & 0.05 \\
\hline 4.6 . & & 14.83 & 17 & 0.01 & 10 & 1.70 & 0.10 & 0.06 & 5 & 2.94 & 70 & 0.24 & 10 & 10.66 & 89 & .08 \\
\hline 5.6 . & 10 & 14.94 & 0.34 & 0.02 & 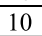 & 1.78 & 99 & 0.05 & 10 & 3.05 & 40 & 0.13 & 10 & 11.12 & \begin{tabular}{|l|}
0.94 \\
\end{tabular} & 0.08 \\
\hline 10.6 . & 8 & 15.35 & 0.25 & 0.02 & 10 & 1.83 & 0.09 & 0.05 & 8 & 3.38 & 10 & 0.12 & 10 & 10.75 & \begin{tabular}{|l|}
0.88 \\
\end{tabular} & 0.08 \\
\hline 11.6 . & 8 & 15.64 & \begin{tabular}{|l|l|}
0.28 \\
\end{tabular} & 0.02 & & 1.87 & 0.09 & 0.05 & 8 & 3.08 & 46 & 0.15 & 7 & 11.44 & \begin{tabular}{|l|}
0.84 \\
\end{tabular} & \begin{tabular}{|l|l|}
0.07 \\
\end{tabular} \\
\hline 12.6. & 9 & 15.85 & 0.33 & 0.02 & 9 & 1.91 & 0.10 & 0.05 & 9 & 3.17 & 44 & 0.14 & 9 & 11.51 & 0.65 & 0.06 \\
\hline all & 52 & 15.23 & 0.49 & 0.03 & 62 & 1.79 & 0.12 & 0.07 & 52 & 3.19 & 0.45 & 0.14 & 59 & 10.94 & 0.86 & 0.08 \\
\hline \multicolumn{17}{|c|}{ Control station KB9998 } \\
\hline 21.9 . & 7 & 16.06 & 0.26 & 0.02 & 7 & 1.85 & 0.13 & 0.07 & 7 & 3.43 & 0.45 & 0.13 & 7 & 11.55 & 0.40 & 0.04 \\
\hline 2.9 . & 6 & 16.25 & $0.2^{2}$ & 0.02 & 8 & 1.92 & 0.05 & 0.03 & 7 & 3.84 & & 0.12 & 5 & 11.17 & $\mid 0.8$ & \begin{tabular}{|l|}
0.08 \\
\end{tabular} \\
\hline 23.9 . & & 16.29 & & 0.01 & & 1.95 & 0.11 & 0.05 & 7 & 3.34 & 0.39 & 0.12 & 8 & 11.60 & 0.75 & \begin{tabular}{|l|l|}
0.07 \\
\end{tabular} \\
\hline 24.9. & 4 & 16.29 & 0.32 & 0.02 & 7 & 1.93 & 0.05 & 0.02 & 5 & 3.93 & 60 & 0.15 & 4 & 11.59 & \begin{tabular}{|l|}
0.44 \\
\end{tabular} & 0.04 \\
\hline 28.9. & 6 & 16.65 & 0.2 & 0.02 & & 1.96 & 0.11 & 0.06 & 6 & 3.61 & & 0.10 & 6 & 11.93 & \begin{tabular}{|l|}
0.60 \\
\end{tabular} & .05 \\
\hline 29.9 . & 6 & 16.15 & 0.2 & 0.02 & 8 & 1.86 & 0.0 & 0.03 & 8 & 3.57 & 0.45 & 0.13 & 7 & 10.99 & 0.36 & 0.03 \\
\hline 30.9 . & 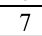 & 16.34 & 0.27 & 0.02 & 8 & 1.94 & 0.12 & 0.06 & 7 & 3.49 & 0.54 & 0.16 & 5 & 10.63 & \begin{tabular}{|l|}
0.97 \\
\end{tabular} & \begin{tabular}{|l|l|}
0.09 \\
\end{tabular} \\
\hline 1.10 . & & 16.54 & \begin{tabular}{|ll} 
\\
\end{tabular} & 0.01 & & 1.92 & 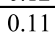 & 0.06 & & 3.62 & & & 8 & 12.21 & 70 & \begin{tabular}{|l|l}
0.06 \\
\end{tabular} \\
\hline 2.10 . & 4 & 16.64 & \begin{tabular}{|l|l|}
0.19 \\
\end{tabular} & 0.01 & 4 & 1.91 & 0.04 & 0.02 & 2 & 3.73 & \begin{tabular}{|l|}
0.02 \\
\end{tabular} & \begin{tabular}{|l|}
0.01 \\
\end{tabular} & 4 & 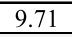 & \begin{tabular}{|l|}
0.53 \\
\end{tabular} & \begin{tabular}{|l|l}
0.06 \\
\end{tabular} \\
\hline all & 54 & 16.35 & 0.30 & 0.02 & \begin{tabular}{|l|}
64 \\
\end{tabular} & 1.92 & 0.09 & 0.05 & \begin{tabular}{|l|l|}
57 \\
\end{tabular} & 3.60 & \begin{tabular}{|l|}
0.45 \\
\end{tabular} & 0.13 & 54 & 11.37 & \begin{tabular}{|l|}
0.89 \\
\end{tabular} & 0.08 \\
\hline
\end{tabular}

Legend: $\mathrm{N}$ - number of measurements,

$\varnothing$ - mean,

$\sigma$ - standard deviation,

$\omega$ - coefficient of variation,

$\mathrm{Ur}-$ unit of concentration of equivalent uranium (1 Ur $\sim 1 \mathrm{ppm} \mathrm{eU})$. 
It follows from the comparison between Table 2 and Table 3 that the analyzed variability rates of the study data sets of repeated measurements at the control stations were markedly decreased through the exclusion of extreme values but they always exceed (except for potassium) both the typical values cited in IAEA (1990) and the values of laboratory measurements. For illustration, the complex of standard deviations is presented in Table 4 and the differences in average standard deviations between the study measurements and IAEA (1990) are presented in Table 5.

Table 4. Outline of standard deviations

\begin{tabular}{|c|c|c|c|c|}
\hline Source & $\begin{array}{c}\text { Total } \\
\text { gamma } \\
{[\mathrm{Ur}]}\end{array}$ & $\begin{array}{c}\text { Potassium } \\
{[\% \mathrm{~K}]}\end{array}$ & $\begin{array}{l}\text { Uranium } \\
\text { [ppmeU] }\end{array}$ & $\begin{array}{l}\text { Thorium } \\
\text { [ppmeTh] }\end{array}$ \\
\hline Laboratory measurements $18.5 .-3.10 .2006$ & \pm 0.12 & \pm 0.05 & \pm 0.20 & \pm 0.35 \\
\hline KB9999 measurements 2. -12.6 .2006 & \pm 0.58 & \pm 0.12 & \pm 0.83 & \pm 0.98 \\
\hline $\begin{array}{l}\text { KB9999 measurements } 2 .-12.6 .2006 \text { after } \\
\text { extreme exclusion }\end{array}$ & \pm 0.49 & \pm 0.12 & \pm 0.45 & \pm 0.86 \\
\hline KB9998 measurements 21.9. - 2.10.2006 & \pm 0.41 & \pm 0.09 & \pm 0.59 & \pm 1.10 \\
\hline $\begin{array}{l}\text { KB9998 measurements 21.9. }-2.10 .2006 \\
\text { after extreme exclusion }\end{array}$ & \pm 0.30 & \pm 0.09 & \pm 0.45 & \pm 0.89 \\
\hline IAEA, 1990 & $\mathrm{n} / \mathrm{a}$ & \pm 0.10 & \pm 0.30 & \pm 0.60 \\
\hline
\end{tabular}

Legend: Ur - unit of concentration of equivalent uranium (1 Ur $\sim 1 \mathrm{ppm} \mathrm{eU})$.

Table 5. Differences in standard deviations between the study results and IAEA (1990)

\begin{tabular}{|l|c|c|c|c|}
\hline \multicolumn{1}{|c|}{ Source } & $\begin{array}{c}\text { Total } \\
\text { gamma } \\
{[\mathrm{Ur}]}\end{array}$ & Potassium & Uranium & Thorium \\
{$[\% \mathrm{~K}]$} & {$[\mathrm{ppmeU}]$} & {$[\mathrm{ppmeTh}]$} \\
\hline Laboratory measurements 18.5. -3.10.2006 & $\mathrm{n} / \mathrm{a}$ & -0.05 & -0.10 & -0.25 \\
\hline KB9999 measurements 2. -12.6 .2006 & $\mathrm{n} / \mathrm{a}$ & +0.02 & +0.53 & +0.38 \\
\hline $\begin{array}{l}\text { KB9999 measurements 2. }-12.6 .2006 \text { after } \\
\text { extreme exclusion }\end{array}$ & $\mathrm{n} / \mathrm{a}$ & +0.02 & +0.15 & +0.26 \\
\hline KB9998 measurements 21.9. - 2.10.2006 & $\mathrm{n} / \mathrm{a}$ & -0.01 & +0.29 & +0.50 \\
\hline $\begin{array}{l}\text { KB9998 measurements 21.9. }-2.10 .2006 \\
\text { after extreme exclusion }\end{array}$ & $\mathrm{n} / \mathrm{a}$ & -0.01 & +0.15 & +0.29 \\
\hline
\end{tabular}

Legend: $\mathrm{Ur}$ - unit of concentration of equivalent uranium $(1 \mathrm{Ur} \sim 1 \mathrm{ppm} \mathrm{eU})$. 


\section{Conclusions}

The results document the theme of measurement stability with the portable gamma-ray spectrometer GS256. Two data sets of repeated measurements were gathered in the year 2006. One of them in laboratory conditions in the period 18.5.-3.10.2006 and the other one in natural conditions at two control stations in the survey area (at the KB9999 in period 2.-12.6.2006 and at the KB9998 in period 21.9.-2.10.2006). Their statistical evaluation showed very good stability of laboratory measurements and much worse stability in natural conditions under the influence of meteorological factors. Better statistical parameters were obtained after the exclusion of values measured during the extreme meteorological conditions (rain, dew, dry) but these ones also exceeded both the laboratory results and the typical values cited in literature $(I A E A, 1990)$. The reasons might be based on another influences, e.g. the temperature dependence of the scintillation crystal, too short accumulation time, etc. The exception is represented by the values measured in the potassium window which stay stable also in situ and thus often serve as a functionality test of airborne gamma-ray spectrometric instruments. The results and the procedures for their acquisition confirm an enormous importance to avoid measurement in inappropriate climatic conditions, the necessity of managing the high-quality remarks on measurement conditions in the field book and also the fact that it is not possible to expect better instrument sensitivity as cited in literature, i.e. $0.2 \% \mathrm{~K}, 1 \mathrm{ppm} \mathrm{eU}$ and $1 \mathrm{ppm}$ eTh (Mareš et al., 1990).

Acknowledgments. This contribution was prepared within the ambit of the project VEGA No. 1/3073/06 "Influence of soil transportation properties in unsaturated zone on their resistivity picture".

\section{References}

IAEA, 1990: The Use of Gamma Ray Data to Define the Natural Radiation Environment. IAEA-TECDOC-566, IAEA, Vienna, 1-48.

Mareš S., Gruntorád J., Hrách S., Karous M., Marek F., Matolín M., Skopec J., 1990: Introduction to Applied Geophysics. SNTL, Prague. 